www.jmscr.igmpublication.org

Index Copernicus Value: 79.54

ISSN (e)-2347-176x ISSN (p) 2455-0450

crossref DOI: https://dx.doi.org/10.18535/jmscr/v7i4.78

Journal Of Medical Science And Clinical Research

IGM Publication

An Official Publication of IGM Publication

\title{
PPIUCD- Acceptance Analysis in Patna Medical College hospital
}

\author{
Authors \\ Dr Rupam Sinha ${ }^{1}$, Dr Ruchi Prasad ${ }^{2}$, Dr Pinky Priya ${ }^{3}$ \\ ${ }^{1}$ Associate Professor, Department of Obst \& Gynae, Patna Medical College \& Hospital, Patna \\ ${ }^{2}$ Senior Resident, Department of Obst. \& Gynae, Patna Medical College, Patna \\ ${ }^{3}$ PG Student, Department of Obst \& Gynae, Patna Medical College, Patna, India
}

\begin{abstract}
Indian women have more children than desired and often too closely together, due to limited choice and awareness of available family planning services. Intra uterine contraceptive devices have been used by women in India since decades for spacing pregnancy. Our study intended to determine the acceptance and refusal of PPIUCD after structured counseling in mother delivering at our institute. We have also analyzed various barriers for not accepting PPIUCD insertion as method of contraception.

Methods: An interventional study was carried among 200 pregnant mothers visiting RCH clinic of P.M.C.H during the period of January 2018 to December 2018 (1 year).They were counseled about the need and choice available for post partum contraceptive methods including PPIUCD. All these 200 mothers met the eligibility criteria. Her willingness to PPIUCD use and in case she refuses, reasons for rejection were noted .Data was analyzed and statistical inferences were drawn by applying test of significance such as chi square test etc.

Results: Acceptance for PPIUCD among participants before counseling was $14.8 \%$. Most common reasons for rejecting PPIUCD was fear of malignancy in 110 women (62\%). With the help of counseling acceptance increased to 48\%. Among all these women who accepted PPIUCD antenatally, 60 women (30\%) allowed post partum insertion. So the actual PPIUCD insertion rate comes to $30 \%$.

Interpretation \& Conclusion: Well structured and balanced counseling provided during antenatal period significantly increases acceptance rate of PPIUCD. Fear of side effects of IUCD was the major hurdle for rejection noted during the study.

Keywords: PPIUCD, Family Planning, Post partum contraception.
\end{abstract}

\section{Introduction}

India has one of the highest mortalities in the world. As published by Zhu and Rustin, short interval between birth are linked to higher maternal and children mortality and morbidity with negative consequences such as low birth weight and preterm birth.

Half of all pregnancy are unplanned and these pregnancies are associated with adverse pregnancy behaviour and outcomes, including late prenatal care, increased incidence of low birth weight and decreased breast feeding as stated by Gipson et al.

Over the years, family planning programs have played a major role in raising contraceptive practice prevalence from $10 \%$ to more than $50 \%$ and reducing fertility in developing countries from six to about three births per women. The post 
partum period is critical time to address high unmet family planning need and to reduce the risks of closely spaced pregnancies as published by Graffield et al. Family planning can overt nearly one third of maternal death and $10 \%$ of infant mortality when couples space their pregnancies more than two years apart. Post partum women need as range of effective contraceptive methods to prevent an unplanned pregnancy within a short interval. These methods include barrier method, oral contraceptives, implants, injectables, breast feeding, and natural family planning methods. IUCD are effective, reversible and can be inserted as early as 10 minutes following placental delivery. The modern IUCD $380 \mathrm{~A}$ is highly effective, safe, long acting, coitus independent and rapidly reversible method of contraception with few side effects. It is the most cost effective method of contraception today. It is also very convenient because it required little action once it is placed. Despite the high rate of expulsion, post partum insertion of $\mathrm{Cu}-\mathrm{T}$ has a role in family planning in the rural setting where women come to the hospital only for delivery.

Intrauterine contraceptive device (IUCD) insertion is convenient and efficient in post placental and immediate post partum periods. Insertion at these time is demonstrably safe, having low incidence of infection, few bleeding problems and low perforation rates. IUCD expulsion rates vary widely depending on timing, type of IUCD and technique of insertion.

In India, although a numbers of contraceptive choices are available, the usage of contraceptive method among postpartum women is rather low. The current study intend to determine acceptance and actual rate of PPIUCD insertion and to analyze barrier for PPIUCD insertion.

\section{Method}

An interventional study was carried among the pregnant mothers visiting antenatal outdoor patient department (RCH) of P.M.C .H during their 28 to 36 weeks of pregnancy over period of 12 months starting from January 2018 to December 2018.

The sample size for this study was 210.Those who were known case of STI $\backslash$ RTI and had history of medical diseases like heart disease, jaundice or known case of intramural $\backslash$ submucous fibroid or congenital malformation of uterus etc were excluded from the study. The study protocols were approved by the Ethics Committee, Patna medical college.

Mothers attending R.C.H clinic of P.M.C.H were counseled about needed choice available for postpartum contraceptive, her views and opinion and reason for rejection were noted.

\section{Result}

Table 1 Acceptance rate of PPIUCD

\begin{tabular}{|c|c|c|c|}
\hline & Pre-counseling & $\begin{array}{c}\text { Post-counseling } \\
\text { (Verbal acceptance) }\end{array}$ & $\begin{array}{l}\text { Chi } \\
\text { square }\end{array}$ \\
\hline $\begin{array}{l}\text { Decision to use } \\
\text { PPIUCD }\end{array}$ & Number of participants $(\mathrm{N}=200)$ Frequency $(\%)$ & Number of participant $(\mathrm{N}=200)$ frequency $(\%)$ & \\
\hline Acceptance & $14 \%$ & $48 \%$ & \\
\hline Rejection & $86 \%$ & $52 \%$ & \\
\hline
\end{tabular}

Acceptance of PPIUCD among the participant before counseling was $14 \%$.Structured counseling increased the acceptance to $48 \%$.This result was statistically significant with $\mathrm{p}<0.001$. Most common reason for rejecting PPIUCD was fear of pain in $62 \%$ women.
Factor affecting rejection by women. Reason for refusal or rejection after structured counseling were the following-

Table 2 Refusal of PPIUCD reasons-

\begin{tabular}{|l|c|c|}
\hline & Number & $\%$ \\
\hline Patient not willing & 40 & 41 \\
\hline Others not willing & 64 & 59 \\
\hline Husband not willing & 42 & 34.45 \\
\hline Mother in law not willing & 22 & 24.55 \\
\hline
\end{tabular}


Want some other method-

- Condom

- OCP

- Ligation later

Fear associated with IUCD

- Menorrhagia 31

- Infertility 3

- Malignancy 34

- Pain

- Others

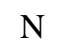

$\%$

$2 \%$

$1.5 \%$

$5 \%$

$30 \%$

$2.8 \%$

$33 \%$

$22 \%$

$12.2 \%$

Table 3 Actual insertion rate of PPIUCD

\begin{tabular}{|l|c|c|c|}
\hline & $\begin{array}{c}\text { Post } \\
\text { counseling } \\
\text { (verbal } \\
\text { acceptance) }\end{array}$ & $\begin{array}{c}\text { Post Delivery } \\
\text { (actual } \\
\text { insertion) }\end{array}$ & $\begin{array}{c}\mathrm{P} \\
\text { value } \\
<0.001\end{array}$ \\
\hline Decision to use & $\begin{array}{c}\text { Number of } \\
\text { participant } \\
\text { PPIUCD }\end{array}$ & $\begin{array}{c}\text { Number of } \\
\text { participant } \\
\text { (N=200) }\end{array}$ & \\
Frequency(\%) & Frequency(\%) & \\
\hline Acceptance & 96 & 78 & \\
\hline Rejection & $48 \%$ & $39 \%$ & \\
\hline
\end{tabular}

Among all the women who accepted PPIUCD verbally antenatally, 78 allowed postpartum insertion, so the actual PPIUCD insertion rate comes to $39 \%$ (table 3).

\section{Discussion}

Postpartum period is one of the critical times when both women and newborn need a special and integrated package of health services as morbidity and mortality rates are quite high during this period. The immediate postpartum period is a particularly favourable time for IUCD insertion. Women who have recently given birth are often highly motivated to use contraception. In addition, women are at risk of an unintended pregnancy in the period immediately after delivery.

Counseling helped women to understand many benefits of PPIUCD over other methods. A large number of women who have chosen this method post counseling, did so as it was not interfering with their breast feeding practice. Other reasons reported by women for choosing PPIUCD, were its immediate reversibility and long term protection. With the help of counseling we were able to achieve statistically significant change in percentage of women having positive attitude

towards use of PPIUCD ( $\mathrm{p}$ value < 0.001). Most common reason for not choosing IUCD was fear of side effects, bleeding, and malignancy as top, and other reasons were family member's advice, religious belief, risk of expulsion and previous bad experience.

As per our study PPIUCD acceptance rate was increased from $14 \%$ to $48 \%$ in post counseling session during antenatal period. All these women who accepted it, were followed up during and after their delivery and out of these only 78 women actually consented post delivery for PPIUCD insertion. Rest of women who accepted conceptually refuse it later. Most of them (50\%) were trying to postpone insertion procedure as they were feeling exhausted because of labour pain.

\section{Conclusion}

Findings from the study provide evidence that well structured and balanced counseling provided during antenatal period significantly increase acceptance rate of PPIUCD. Fear of side effect was the major hurdle, which if addressed carefully, can convince women to use PPIUCD as their preferred post partum contraception.

\section{References}

1. Zhu BP effect of inter pregnancy interval on birth outcomes findings from three recent US studies. International journal of Gynaecology \& Obstetrics. 2005 Apr.30; $89: 525-33$

2. Gipson JD, kosnig MA, Husdin MJ. The effect of unintended pregnancy on infant, child, and parental health; a review of the literature. Studies in family planning. 2008 Mar 1: 39 (1); 18-38

3. Gaffield ME, Egan S, Tammermean M. It's about time :WHO and partners release programming strategies for postpartum family planning. Global health ;Science and Practice. 2014 Feb 1; 2 (1): 4-9 
4. Postpartum contraceptive methods. Network (Research Triangle Park, NC) 1940;11(3) 10-1

5. Division FP, Welfare F. Postpartum IUCD Reference Manual 2010; (November)

6. O' Hanley K, Humber DH. Postpartum IUCD; keys for success. Contraception 1992 Apr; 45 (4). 351-61

7. Bharin SK, Pant M, Metha M, Kumar S. Prevalence of usage of different methods in contraceptive East Delhi-A cross sectional study. Indian J Community medicine.2005; 30 (2); 25-7. 